\title{
POTENTIAL OF EGGPLANT PEEL AS BY-PRODUCT
}

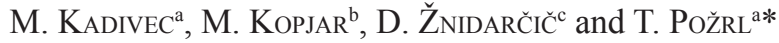 \\ ${ }^{a}$ Department of Food Science and Technology; Biotechnical Faculty, Jamnikarjeva 101, 1000 Ljubljana. Slovenia \\ ${ }^{b}$ Faculty of Food Technology, F. Kuhača 20, 31000 Osijek. Croatia \\ ${ }^{\mathrm{c}}$ Department of Agronomy; Biotechnical Faculty, Jamnikarjeva 101, 1000 Ljubljana. Slovenia
}

(Received: 04 October 2013; accepted: 21 January 2014)

\begin{abstract}
In this study ascorbic acid and phenolic compounds contents of eggplant flesh and eggplant peel were determined. Among the investigated eggplant cultivars generally eggplant peel had higher ascorbic acid and phenolic compounds contents than eggplant flesh. Ascorbic acid content in eggplant flesh ranged from 33.62 to $92.75 \mathrm{mg} \mathrm{kg}^{-1}$ and in eggplant peel from 12.45 to $111.01 \mathrm{mg} \mathrm{kg}^{-1}$. Phenolic compounds content ranged from 11.77 to $22.18 \mathrm{~g} \mathrm{~kg}^{-1}$ in eggplant flesh and from 13.46 to $29.42 \mathrm{~g} \mathrm{~kg}^{-1}$ in eggplant peel. Eggplant peel is usually treated as waste, i.e. byproduct, omitting its potentially beneficial characteristics. Due to higher ascorbic acid and phenolic compounds contents, further investigations should be directed on possible use of eggplant peel as natural ingredient for functional products formulation.
\end{abstract}

Keywords: eggplant peel, eggplant flesh, ascorbic acid, phenolic compounds, by-product

Growing awareness of consumers and their knowledge on health promoting effects of antioxidants on human health, but also consumers' rejection of addition of synthetic antioxidants to food products led to investigation of use of natural antioxidants for food formulations (Peschel et al., 2006). Diet rich in fruit and vegetables is recommended for achieving healthy lifestyle. Up to one third of the volume of fruit and vegetables are in form of peels, seeds, and skins, which is discarded during preparation and processing resulting in waste, i.e. by-products. Discarding the waste usually leads to loss of nutritional value of fruit and vegetables (O'SHEA et al., 2012). Production of by-products is increasing every day and these plant materials represent growing problems due to microbial spoilage that limits its further exploitation. This fact combined with costs of drying, storage, and shipment of byproducts presents economically limiting factors (SCHIEBER et al., 2001). Thus, researchers are seeking new alternative uses of waste, i.e. by-products, as potential value ingredients. Epidemiological studies have shown that fruit and vegetable compounds (like dietary fibre, polyphenols, carotenoids, vitamins, and others) have an effect on human health (SCHIEBER et al., 2001). The interest for antioxidants is increasing due to their capacity of scavenging free radicals and potential to reduce the level of oxidative stress associated with various diseases, such as cardiovascular diseases, certain types of cancer, neurodegenerative diseases, osteoporosis, or inflammation (KRIs-ETHERTON et al., 2002).

There have been studies showing that fruit or vegetable peels are valuable by-products due to their content of many nutrients and antioxidants; thus extracts of peels could be used in formulation of food products for fortification with those compounds. The major concern in previous studies was the determination of dietary fibre and phenolic compounds contents of by-products.

\footnotetext{
* To whom correspondence should be addressed. Phone: +386-1-3203716; e-mail: tomaz.pozrl@bf.uni-lj.si
} 
Eggplant (Solanum melongena L.) is a common vegetable consumed throughout the world and it is particularly rich in antioxidants (KANEYUKI et al., 1999), ranking among the top 10 vegetables in terms of antioxidant capacity (CAO et al., 1996; LutHRIA \& MuKHOPADHYAY, 2006). Eggplant cultivars differ in their fruit size, shape, and colour. Very often eggplant peel is treated as a food waste, i.e. by-product. In this study, eggplant flash and eggplant peel were investigated as sources of bioactive compounds, ascorbic acid and phenolic compounds, which have antioxidant properties and beneficial effect on health, in order to evaluate the possibility to use eggplant peel in food industry as supplement in formulation of food products.

\section{Materials and methods}

\subsection{Material}

Plants were grown at the Experimental Station of the Biotechnical Faculty in Ljubljana (latitude $46^{\circ} 04^{\prime} \mathrm{N}$, longitude $14^{\circ} 31^{\prime} \mathrm{W}, 300 \mathrm{~m}$ above see level). Nine (9) cultivars were studied: Mirabelle, Valentina, Galina, Epic, Medium long, BSS 385, BSS 330, and BSS 332. Only cultivar Epic was grown both in greenhouse and field. Peel was separated from flesh and determination of ascorbic acid and phenolic compounds contents was immediately conducted.

\subsection{Determination of soluble dry matter}

Soluble dry matter was determined by digital refractometer ATAGO PR-1. At five different places of eggplant flesh or eggplant peel sampling was conducted and juice was squeezed from those samples for determination of soluble solids.

\subsection{Determination of ascorbic acid}

Ascorbic acid was determined using HPLC. Six g of eggplant flesh or peel were mixed with $24 \mathrm{~g}$ of $2 \%$ metaphosphoric acid, homogenized with Ultraturrax, and filtered through $0.45 \mu \mathrm{m}$ cellulose acetate filters. Obtained samples were analyzed by HPLC (Marathon-XT autosampler, Knauer isocratic Pump (K-1001), X-Act degassing unit from Jourresearch, Knauer UV-VIS detector, Wellchrom interface box, and personal computer running EuroChrom 2002 software). Ascorbic acid was analyzed on an Aminex HPX-87 H, 300×7.8 $\mathrm{mm}$ (Bio-Rad) chromatographic column with $0.004 \mathrm{M} \mathrm{H}_{2} \mathrm{SO}_{4}$ in Milli-Q water as mobile

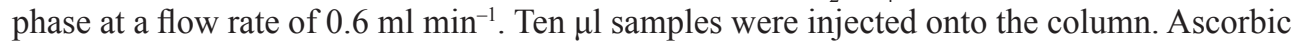
acid was detected at $245 \mathrm{~nm}$. Determination was conducted in triplicates and results were expressed in milligrams of ascorbic acid equivalent per kilogram $\left(\mathrm{mg} \mathrm{kg}^{-1}\right)$ of wet basis.

\subsection{Determination of phenolic compounds content}

The phenolic compounds content was determined using the Folin-Ciocalteu (FC) assay (Sтоuт et al., 1998) with chlorogenic acid as a standard. Phenolic extraction was conducted by extraction procedure described by Fuкuмото and co-workers (2002) with slight modification. Briefly, $10 \mathrm{~g}$ of eggplant flesh or peel was mixed with $20 \mathrm{ml}$ of methanol and homogenized with Ultraturrax for 60 seconds. After homogenization, mixture was left at room temperature for 15 minutes and filtrated through filter paper. Obtained filtrate was centrifuged for 10 minutes at $12000 \mathrm{~min}^{-1}$, supernatant was kept at $-20{ }^{\circ} \mathrm{C}$ prior analyses. 
FC assay was carried out by pipetting $50 \mu \mathrm{l}$ of eggplant extract, $675 \mu \mathrm{l}$ of water and mixing with $125 \mu \mathrm{FC}$ reagent (1:2). After 5 minutes, $125 \mu \mathrm{l}$ of $20 \%$ sodium carbonate solution was added. The mixture was left for 90 minutes and the absorbance of the coloured reaction product was measured at $750 \mathrm{~nm}$. The calibration curve was created using chlorogenic acid as standard solution. The phenolic compounds content in the extract was calculated from the standard calibration curve and results were expressed in grams of chlorogenic acid equivalent (CAE) per kilogram $\left(\mathrm{g} \mathrm{kg}^{-1}\right)$ of dry matter. Determination was conducted in triplicates.

\section{Results and discussion}

Soluble dry matter and ascorbic acid and phenolic compounds contents were determined in eggplant flesh and eggplant peel (Table 1). Soluble dry matter determined by digital refractometer ranged from $3.7 \%$ to $7.2 \%$. Overall, cultivars Epic (greenhouse and field production) and Galina had the lowest soluble dry matter content. Comparing soluble dry matter contents in eggplant flesh and eggplant peel, all samples except Epic (field production) and Galina, had higher soluble dry matter contents in eggplant peel. The highest soluble dry matter content in eggplant peel was found in cultivars Mirabelle, BSS 332, and BSS 330. Comparing soluble dry matter in eggplant flesh, the highest soluble dry matter content was found in cultivars BSS 332, Mirabelle, and BSS 385. The soluble dry solids in eggplants, BSS 332, and Epic (greenhouse and field production) were almost similar in the flesh and peel. Cultivar Epic from greenhouse had slightly higher values of soluble dry solids in peel than in flesh in contrast to cultivar Epic from field production, showing that growth conditions are playing an important part in the chemical composition of plant material. Our results are in accordance with results of PROHENS and co-workers (2007), who investigated 69 eggplant cultivars and found that soluble dry solids ranged from 3.6 to $6.6 \%$.

Table 1. Soluble solids, ascorbic acid, and phenolic compounds contents of eggplant flesh and peel.

\begin{tabular}{|c|c|c|c|c|c|c|}
\hline \multirow[t]{2}{*}{$\begin{array}{l}\text { Eggplant } \\
\text { cultivar }\end{array}$} & \multicolumn{2}{|c|}{$\begin{array}{l}\text { Soluble solids } \\
\text { (\%) }\end{array}$} & \multicolumn{2}{|c|}{$\begin{array}{l}\text { Ascorbic acid } \\
\quad\left(\mathrm{mg} \mathrm{kg}^{-1}\right)\end{array}$} & \multicolumn{2}{|c|}{$\begin{array}{l}\text { Phenolic compounds } \\
\qquad\left(\mathrm{g} \mathrm{kg}^{-1} \mathrm{CAE}\right)\end{array}$} \\
\hline & Flesh & Peel & Flesh & Peel & Flesh & Peel \\
\hline Mirabelle & $6.43 \pm 0.11$ & $7.23 \pm 0.12$ & $47.94 \pm 0.47$ & $48.47 \pm 0.35$ & $17.65 \pm 0.22$ & $29.42 \pm 0.60$ \\
\hline Valentina & $4.57 \pm 0.85$ & $4.85 \pm 0.60$ & $33.62 \pm 0.13$ & $12.45 \pm 0.16$ & $18.12 \pm 0.12$ & $23.73 \pm 0.34$ \\
\hline Galina & $4.63 \pm 0.22$ & $3.88 \pm 0.24$ & $61.26 \pm 0.60$ & $38.91 \pm 0.55$ & $21.65 \pm 0.22$ & $23.09 \pm 0.29$ \\
\hline Epic (G) & $3.76 \pm 0.09$ & $4.03 \pm 0.14$ & $55.15 \pm 0.57$ & $68.26 \pm 0.12$ & $14.76 \pm 0.65$ & $17.65 \pm 0.13$ \\
\hline Epic (F) & $3.91 \pm 0.12$ & $3.58 \pm 0.12$ & $59.87 \pm 0.12$ & $42.51 \pm 0.59$ & $13.57 \pm 0.14$ & $16.70 \pm 0.12$ \\
\hline $\begin{array}{l}\text { Medium } \\
\text { long }\end{array}$ & $4.37 \pm 0.09$ & $6.25 \pm 0.50$ & $61.66 \pm 0.65$ & $96.13 \pm 0.56$ & $12.49 \pm 0.19$ & $14.72 \pm 0.22$ \\
\hline BSS 385 & $5.96 \pm 0.94$ & $6.22 \pm 0.45$ & $51.31 \pm 0.14$ & $100.97 \pm 0.19$ & $11.77 \pm 0.47$ & $13.46 \pm 0.42$ \\
\hline BSS 330 & $5.75 \pm 0.78$ & $6.88 \pm 0.33$ & $49.71 \pm 0.22$ & $93.27 \pm 0.35$ & $21.52 \pm 0.57$ & $25.21 \pm 0.08$ \\
\hline BSS 332 & $6.66 \pm 0.23$ & $6.76 \pm 0.27$ & $92.75 \pm 0.98$ & $111.01 \pm 0.11$ & $22.18 \pm 0.33$ & $22.72 \pm 0.35$ \\
\hline
\end{tabular}

G: eggplants grown in greenhouse; F: eggplants grown in field; CAE: chlorogenic acid equivalent 
Ascorbic acid content ranged from $12.45 \mathrm{mg} \mathrm{kg}^{-1}$ to $111.01 \mathrm{mg} \mathrm{kg}^{-1}$ (Table 1). Comparing all samples, both of the eggplant flesh and peel, cultivar Valentina had the lowest ascorbic acid content. The highest ascorbic acid content, both in flesh and peel, was observed in cultivar BSS 332 (92.75 mg kg-1 and $111.01 \mathrm{mg} \mathrm{kg}^{-1}$, respectively). In all cultivars different ascorbic acid contents in flesh or peel were observed, except in cultivar Mirabelle. Cultivars BSS 332, BSS 385, BSS 330, Medium long, and Epic (greenhouse production) had higher ascorbic acid content in eggplant peel. In the eggplant peel of those cultivars ascorbic acid content ranged from $68.26 \mathrm{mg} \mathrm{kg}^{-1}$ to $111.01 \mathrm{mg} \mathrm{kg}^{-1}$, while in the eggplant flesh those values ranged from $55.15 \mathrm{mg} \mathrm{kg}^{-1}$ to $92.75 \mathrm{mg} \mathrm{kg}^{-1}$. Cultivars Galina and Epic (field production) showed different tendency, in those cultivars eggplant flesh $\left(61.26 \mathrm{mg} \mathrm{kg}^{-1}\right.$ and 59.87 $\mathrm{mg} \mathrm{kg}{ }^{-1}$, respectively) had higher ascorbic acid content than eggplant peel $\left(38.91 \mathrm{mg} \mathrm{kg}^{-1}\right.$ and $42.51 \mathrm{mg} \mathrm{kg}^{-1}$, respectively). Ji and co-workers (2011) observed higher amount of ascorbic acid in eggplant peel $(51.88 \mathrm{mg} / 100 \mathrm{~g})$ than in eggplant pulp $(12.93 \mathrm{mg} / 100 \mathrm{~g})$. Ascorbic acid

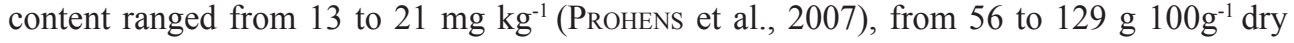
weight basis (HANSON et al., 2006), from 2.91 to $6.54 \mathrm{mg} / 100 \mathrm{~g}$ (SAN José et al., 2013) in different studies.

Phenolic compounds contents (eggplant flesh and peel) of different eggplant cultivars are presented in Table 1. In all eggplant samples the higher phenolic compounds content values were in eggplant peel, probably due to presence of different phenolic compounds, including anthocyanins. HuANG and co-workers (2004) and JI and co-workers (2011) also found that eggplant peel had higher phenolic compounds content, and it was about two and four times greater than in eggplant pulp. The highest phenolic compounds content in eggplant flesh was found in cultivars BSS 332, Galina, and BSS 330 (22.18 g kg-1, $21.65 \mathrm{~g} \mathrm{~kg}^{-1}$ and $21.52 \mathrm{~g} \mathrm{~kg}^{-1}$, respectively), and the lowest BSS $385\left(11.77 \mathrm{~g} \mathrm{~kg}^{-1}\right)$. Cultivars Mirabelle and BSS 330 had the highest phenolic compounds contents in eggplant peel $\left(29.42 \mathrm{~g} \mathrm{~kg}^{-1}\right.$ and $25.21 \mathrm{~g} \mathrm{~kg}^{-1}$, respectively), and BSS 385 and Medium long had the lowest (13.46 $\mathrm{g} \mathrm{kg}^{-1}$ and $14.72 \mathrm{~g} \mathrm{~kg}^{-1}$, respectively). Overall looking, cultivars BSS 385 and Medium long had the lowest phenolic compounds contents.

There have been studies on the determination of phenolic compounds in eggplant; depending on studies, whole eggplant or its parts (flesh or peel) were used for evaluation. JI and co-workers (2011) observed higher amount of phenolic compounds in eggplant peel ( $\sim 90.65 \mathrm{mg}$ gallic acid equivalent, GAE/100 $\mathrm{g}$ fresh weight) than in eggplant pulp ( 21.13 mg GAE/100 g fresh weight). ToDARO and co-workers (2009) determined $188 \mathrm{mg} \mathrm{GAE} / 100 \mathrm{~g}$ in fresh peel. Determination of phenolic compounds in whole eggplant resulted in different values, from 280 to $834 \mathrm{mg}$ CAE/ $\mathrm{kg}$ fresh weight (ProhENs et al., 2007), from 0.74 to $1.43 \mathrm{~g}$ CAE/100 g dry weight (HANSON et al., 2006), 80.31 to $106.98 \mathrm{mg} \mathrm{GAE} / 100 \mathrm{~g}$ of fresh weight (Nisha et al., 2009), $90 \mathrm{mg}$ GAE/100 g of fresh weight (Song et al., 2010), and from 41 to $81.7 \mathrm{mg} \mathrm{CAE} / 100 \mathrm{~g}$ of fresh weight (SAN José et al., 2013). Values of phenolic compounds content of eggplant flesh in previous studies were from 1.1 to $1.3 \mathrm{mg}$ GAE/g of fresh weight (Hu et al., 2010) and from 8.14 to $22.47 \mathrm{~g} \mathrm{CAE} / \mathrm{kg}$ of dry weight (PlazAs et al., 2013). MenNella and co-workers (2012) determined phenolic compounds in various stages of ripening of eggplant and determined that phenolics varied from 1.94 to $4.66 \mathrm{~g} \mathrm{CAE} / 100 \mathrm{~g}$ of dry weight for unripe, from 1.41 to $2.8 \mathrm{~g} \mathrm{CAE} / 100 \mathrm{~g}$ of dry weight for commercially ripe, and from 1.46 to $3.18 \mathrm{~g} \mathrm{CAE} / 100 \mathrm{~g}$ of dry weight for physiological ripe eggplant.

Lots of studies revealed that fruit and vegetable peel have higher phenolic compounds content and antioxidant activity than fruit and vegetable flesh, and usually peel is treated as a waste. Also, there have been lots of studies showing that peel can be useful by-product and 
used in formulation of food products, due not only to peel compounds health benefits but also to positive effect on food product quality. There have been studies proving beneficial effect of eggplant or eggplant skin extracts on human health like suppression of the development of blood vessels required for tumour growth and metastasis (MATSUBARA et al., 2005), inhibition of protein-activated receptor 2 inflammation that can lead to atherosclerosis (HAN et al., 2003), and scavenging of superoxide free radicals and inhibition of hydroxyl radical generation (KANEYUKI et al., 1999; NODA et al., 2000). Superoxide radicals generated in vivo are usually converted into hydrogen peroxide, and like other free radicals, can damage lipids, proteins, and DNA (HALLiwell et al., 1995). SINGH and co-workers (2009) correlated the LDL antioxidant activity with the phenolic content of the investigated eggplant cultivars.

In most articles eggplants phenolic compounds are mostly described as the important class of antioxidants, giving less attention to ascorbic acid, which is also present in eggplant. There have been studies (HAnson et al., 2006; Prohens et al., 2007; SingH et al., 2009; Hu et al., 2010) on determination of eggplant phenolic compounds content and ascorbic acid content. As far as we know, none of those studies emphasise eggplant peel as potential valuable by-product. Comparing our results to the literature, differences were observed. These could be due to differences in the experimental part of the investigation, like sample preparation, methods used for the determination, and expression units of ascorbic acid and phenolic compounds content. Nevertheless, data of determination of ascorbic acid and phenolic compounds contents of eggplant peel revealed that eggplant peel is a valuable byproduct and could be used in the food industry for fortification of food products with antioxidants.

\section{Conclusions}

The objective of this study was to determine the ascorbic acid and phenolic compounds contents of eggplant flesh and eggplant peel. Usually peel is removed before eggplant preparation for consumption or processing, leading to ascorbic acid and phenolics loss. Eggplant peel is a valuable source of ascorbic acid and phenolics, thus it would be possible to use eggplant peel in food formulations. Characterization of eggplant peel phenolics should be conducted and their effect on human health determined. Also, possible application of eggplant peel to food products as natural ingredient and its influence on overall food products quality, especially sensory properties, should be investigated.

\section{References}

CAo, G., Sofic, E. \& Prior, R.L. (1996): Antioxidant capacity of tea and common vegetables. J. Agric. Food Chem., 44, 3426-3431.

Funumoto, L.R., Toivonen, P.M.A. \& Delaquis, P.J. (2002): Effect of wash water temperature and chlorination on phenolic metabolism and browning of stored Iceberg lettuce photosynthetic and vascular tissues. J. Agric. Food Chem., 50, 4503-4511.

Halliwell, B., Aeschbach, R., Löliger, J. \& Arouma, O.I. (1995): The characterization of antioxidants. Food Chem. Toxicol., 33, 601-617.

Han, S.W., Tae, J., Kim, J.A., Kim, D.K., Seo, G.S., Yun, K.J., Choi, S.C., Kim, T.Y., Nah, Y.H. \& LeE, Y.M. (2003): The aqueous extract of Solanum melongena inhibits PAR2 agonist-induced inflammation. Clin. Chim. Acta, 328, 39-44. 
Hanson, P.M., Yang, R.Y., Tsou, S.C.S., Ledesma, D., Engle, L. \& Lee, T.C. (2006): Diversity in eggplant (Solanum melongena) for superoxide scavenging activity, total phenolics, and ascorbic acid. J. Food Compos. Anal., 19, 594-600.

Hu, W., Jiang, A., Tian, M., Liu, C. \& Wang, Y. (2010): Effect of ethanol treatment on physiological and quality attributes of fresh-cut eggplant. J. Sci. Food Agric., 90, 1323-1326.

Huang, H.Y., Chang, C.K., Tso, T.K., Huang, J.J., Chang, W.W. \& Tsai, Y.C. (2004): Antioxidant activities of various fruits and vegetables produced in Taiwan. Int. J. Food Sci. Nutr., 55, 423-429.

Ji, L., Wu, J., GaO, W., WeI, J., Yang, J. \& Guo, C. (2011): Antioxidant capacity of different fractions of vegetables and correlation with the contents of ascorbic acid, phenolics, and flavonoids. J. Food Sci., 76, C1257-C1261.

Kaneyuki, T., Noda, Y., Traber, M.G., Mori, A. \& Packer, L. (1999): Superoxide anion and hydroxyl radical scavenging activities of vegetable extracts measured using electron spin resonance. Biochem. Mol. Biol. Int., 47, 979-989.

Kris-Etherton, P., Hecker, K., Bonanome, A., Coval, S., Binkoski, A., Hilpert, K., Griel, A.E. \& Etherton, T.D. (2002): Bioactive compounds in foods: their role in the prevention of cardiovascular disease and cancer. Am. J. Med., 113, 71-88.

Luthria, D.L. \& Mukhopadhyay, S. (2006): Influence of Sample Preparation on assay of phenolic acids from eggplant. J. Agr. Food Chem., 54, 41-47.

Matsubara, K., Kaneyuki, T., Miyake, T. \& Mori, M. (2005): Antiangiogenic activity of nasunin, an antioxidant anthocyanin, in eggplant peels. J. Agr. Food Chem., 53, 6272-6275.

Mennella, G., Lo Scalzo, R., Fibiani, M., D’Alessandro, A., Francese, G., Toppino, L., Acciarri, N., De Almeida, A.E. \& Rotino, G.L. (2012): Chemical and bioactive quality traits during fruit ripening in eggplant (S. melongena L.) and allied species. J. Agr. Food Chem., 60, 11821-11831.

Nisha, P., Abdul Nazar, P. \& Jayamurthy, P. (2009): A comparative study on antioxidant activities of different varieties of Solanum melongena. Food Chem. Toxicol., 47, 2640-2644.

Noda, Y., Kaneyuki, T., Igarashi, K., Mori, A. \& Packer, L. (2000): Antioxidant activity of nasunin, an anthocyanin in eggplant peels. Toxicol., 148, 119-123.

O’Shea, N., Arendt, E.K. \& Gallagher, E. (2012): Dietary fibre and phytochemical characteristics of fruit and vegetable by-products and their recent applications as novel ingredients in food products. Innov. Food Sci. Emerg., 16, 1-10.

Peschel, W., Sánchez-Rabaneda, F., Diekmann, W., Plescher, A., Gartzía, I., Jiménez, D., Lamuela-Raventós, R., Buxaderas, S. \& Codina, C. (2006): An industrial approach in the search of natural antioxidants from vegetable and fruit wastes. Food Chem., 97, 137-150.

Plazas, M., López-Gresa, M.P., Vilanova, S., Torres, C., Hurtado, M., Gramazio, P., Andújar, I., Herráiz, F.J., Bellés J.M. \& Prohens, J. (2013): Diversity and relationships in key traits for functional and apparent quality in a collection of eggplant: Fruit phenolics content, antioxidant activity, polyphenol oxidase activity, and browning. J. Agr. Food Chem., 61, 8871-8879.

Prohens, J., Rodríguez-Burruezo, A., Raigón, M.D. \& Nuez, F. (2007): Total phenolic concentration and browning susceptibility in a collection of different varietal types and hybrids of eggplant: Implications for breeding for higher nutritional quality and reduced browning. J. Am. Soc. Hortic. Sci., 132, 638-646.

San José, R., Sánchez, M.C., Cámara, M.M. \& Prohens, J. (2013): Composition of eggplant cultivars of the Occidental type and implications for the improvement of nutritional and functional quality. Int. J. Food Sci. Tech., 48, 2490-2499.

Schieber, A., Stintzing, F.C. \& Carle, R. (2001): By-products of plant food processing as a source of functional compounds - recent developments. Trends Food Sci. Tech., 12, 401-413.

Singh, A.P., Luthria, D., Wilson, T., Vorsa, N., Singh, V., Banuelos, G.S. \& Pasakdee, S. (2009): Polyphenols content and antioxidant capacity of eggplant pulp. Food Chem., 114, 955-961.

Song, W., Derito, C.M., Keshu Liu, M., He, X., Dong, M. \& Hai Liu, R. (2010): Cellular antioxidant activity of common vegetables. J. Agric. Food Chem., 58, 6621-6629.

Stout, M., Brovont, R.A. \& Duffey, S.A. (1998): Effect of nitrogen availability on expression of constitutive and inducible chemical defences in tomato. J. Chem. Ecol., 24, 945-963.

Todaro, A., Cimino, F., Rapisarda, P., Catalano, A.E., Barbagallo, R.N. \& Spagna, G. (2009): Recovery of anthocyanins from eggplant peel. Food Chem., 114, 434- 439. 